\title{
LA COMUNICACIÓN GENÉTICA DESDE LA PERSPECTIVA DE LOS SISTEMAS SOCIALES ${ }^{1}$
}

\author{
Marcelo Arnold Cathalifaud*
}

Resumen: En este artículo se aplica la teoría de los sistemas sociales para analizar las repercusiones de las aplicaciones biocientíficas en la sociedad contemporánea y explicar el posicionamiento del riesgo como un medio habitual de comunicación. Desde esta perspectiva, trata la investigación genética como un problema emergente y autoproducido, que apunta a situaciones que las sociedades latinoamericanas recién empiezan a enfrentar. Los objetivos fueron relacionar, desde una observación de segundo orden, comunicaciones que van desde los alimentos transgénicos hasta las expectativas generadas por la investigación genómica. Finalmente, se indican los medios que incrementan en complejidad las operaciones sociales involucradas en la comunicación genética y que guían su evolución, como es el caso de la comunicación bioética.

Palabras clave: Complejidad social, teoría de sistemas sociales, biociencias, bioética, riesgos

\section{A REPORT OF GENETICS FROM A SOCIAL SYSTEM PERSPECTIVE}

\begin{abstract}
In this article social system theory was applied in order to analyze the repercussions of bioscientific applications in contemporary society, and furthermore in order to explain the risk status of a habitual means of communication. From this perspective, genetic research is treated as an emerging problem one, which is self-made, that aims at situations which Latin American society has only just recently begun to face. The objectives of this study were to relate, from an observation of the second order, reports that were from genetically modified foodstuffs to the expectations generated by genetics research. Finally, this article indicates that the complexity is raised in social operations which will involve communication in genetics, communication that will guide its evolution, as is the case with communication in Bioethics.
\end{abstract}

Keywords: Social complexity, social systems theory, biosciences, bioethics, risks

\section{A COMUNICAÇÃO GENETICA DO PERSPECTIVE DOS SISTEMAS SOCIAIS}

Resumo: Este artigo aplica a teoria dos sistemas sociais para analisar as repercussões das intervenções biotecnocientíficas na sociedade contemporânea; busca, também, explicar o posicionamento do risco como meio habitual de comunicação. Nessa perspectiva, considera a investigação genética como problema emergente e autoproduzido que aponta para situações que as sociedades latinoamericanas apenas começam a enfrentar. Os objetivos são de relacionar as comunicações relativas ao espectro que vai dos alimentos transgênicos até as expectativas geradas pela investigação genômica. Finalmente, apontam-se os meios que aumentam em complexidade as operações sociais envolvidas na comunicação genética e que orientam sua evolução, como é o caso da comunicação bioética.

Palavras chave: Complexidade social, teoria de sistemas sociais, biociencias, bioética, riscos

\footnotetext{
Este documento comprende el marco teórico del Proyecto Antropología Social del Genoma Humana, (SOO-06/2) que me corresponde dirigir, y que es auspiciado por el Departamento de Investigación de la Universidad de Chile. La Información general contenida en el artículo fue extraída de revistas y periódicos de circulación nacional, de la INTERNET y de entrevistas desarrolladas a científicos y profesionales para el Proyecto sobre Comunicación Genética y sus implicancias, desarrollado por los autores en la Facultad de Ciencias Sociales de la Universidad de Chile.

Se agradecen los aportes de los colegas Fernando Robles, Francisco Osorio y Aldo Mascareño y la revisión de la antropóloga Carolina Valdebenito. Especial reconocimiento a los sociólogos españoles Pablo Navarro, José María García Blanco, Josetxo Beriain y Juan Luis Pintos por sus comentarios. Como es obvio, las insuficiencias que persisten son de nuestra exclusiva responsabilidad.

* Profesor del Departamento de Antropología de la Facultad de Ciencias Sociales de la Universidad de Chile. Correspondencia: marnold@uchile.cl
} 
Comunicación Genética y Sistemas Sociales - M. Arnold demás.

Nada es simple, todo depende de todo lo

\section{Emergencia del problema desde la observación de la sociedad}

Las naciones contemporáneas más desarrolladas fundaron sus logros en la creciente ampliación de los derechos individuales, en la generalización de formas democráticas de gobierno, en la asignación de recursos sobre la base del mercado, en el conocimiento científico y tecnológico y en la instrumentalización de los vínculos sociales por medio de las organizaciones formales. Sus procesos se asocian con una acentuada diferenciación en sistemas parciales que se despliegan sin reconocer restricciones, salvo las contenidas en estructuras que hacen referencia a sus operaciones autorreferenciales(1). Por ejemplo, las actividades científicas asumen la búsqueda de la verdad como su criterio central y son indiferentes a otros requerimientos; en el otro extremo el sistema de la ética se desacopla de los intereses religiosos, económicos y políticos para revelar lo bueno(2) a través de sus distinciones entre lo ético y lo no ético. Tales sistemas se transnacionalizan y sus fronteras coinciden con el planeta entero.

Garantizando con estos mecanismos sus altas productividades, la sociedad mundial se enfrenta a las consecuencias de los rendimientos que se extraen para beneficios de corto plazo. De acuerdo con Beck(3), dejamos de preocuparnos sobre lo que la naturaleza puede hacernos, cuando los desastres naturales ya se han socializado. Primero fue el entorno ecológico, ahora, gracias a las biotecnologías, concentran la atención nuestras acciones sobre los sistemas vivos. Mientras que por largo tiempo la atención sobre los efectos positivos y negativos del proceso civilizatorio se pusieron en las manipulaciones nucleares y químicas, hoy los focos se concentran en las alteraciones que se producen en organismos, incluyendo la propia biología humana. Específicamente, la comunicación acerca de las proyecciones de las biociencias gatilla gran expectación y empieza a ocupar los primeros planos.

La opinión pública se motiva por las posibilidades que surgen de experimentar con las estructuras de los sistemas vivientes y sus extrapolaciones en las emociones, conciencias y vínculos sociales humanos.

Las biotecnologías son una de las aplicaciones científicas de más rápida generalización a escala planetaria, sus potencialidades multiplican con creces sus actuales usos. Productos apenas comercializados retroalimentan escaladas de inversiones dentro de los mercados tecnológicos del Nasdaq que, a su vez, potencian búsquedas para otros nuevos. Casi la mitad de las patentes registradas por industrias farmacéuticas se están originando en investigaciones biotecnológicas. En Europa y los Estados Unidos existen miles de empresas en biotecnología, cientos de productos recombinados genéticamente son probados en estudios clínicos, muchos otros están en desarrollo. Todo anticipa que durante el siglo veintiuno las bioindustrias moverán miles de millones de dólares. De hecho, los actuales desempeños de los valores asociados al mercado de la salud, que incluye la biotecnología, durante el último decenio han mantenido altos rendimientos. Así, se prevé la proliferación de servicios de diagnósticos genómicos, de terapias génicas, de implantaciones orgánicas e importantes desarrollos de la farmacogenómica ${ }^{2}$ y de las empresas de

\footnotetext{
2 Potencialmente aplicable a cerca de seis mil enfermedades, en cuya causa se identifica la presencia de un gen defectuoso y como refuerzos a los mecanismos inmunológicos de otras miles de dolencias humanas. La primera corrección genética exitosa fue llevada a cabo el año pasado (2000) permitiendo restaurar el sistema inmunológico de dos niños burbuja.
} 
equipamientos médicos para las nuevas circunstancias, como es el caso de los biochips. Con el mapeo del genoma humano se fortalecieron incalculables perspectivas para la biomedicina. Sin duda, su previsión fue un aspecto que influyó para adelantar los resultados de su investigación. En forma paralela, prospera la comercialización de organismos genéticamente modificados que mejorando sustantivamente los estándares de la productividad alimenticia, posibilitan ganado y cultivos de óptima calidad. Hoy, los consumidores llevan a sus mesas cada vez más ingredientes genéticamente modificados Frankenstein food como advierten sus detractores-, especialmente desde que el empleo de sus semillas fue aprobado por la Food and Drug Administration. De hecho, las principales empresas que operan en esta industria, proyectan producir más del $70 \%$ de los alimentos durante este siglo y actualmente, por mandatos jurídicos, bajo el rótulo de transgénicos se clasifican en el comercio internacional miles de productos. Hasta los proteccionistas visualizan en estos medios nuevos recursos para la preservación de especies en peligro de extinción -para empezar osos pandas gigantes, como lo anuncian investigadores chinos.

Sorprende que productos originados en conocimientos científicos que apenas alcanzan las tres décadas, estén complejizando de tal manera la sociedad contemporánea e influyendo tan decisivamente en la evolución humana y social.

Un breve vistazo a tal aceleración toma como punto inicial el año 1973, consignado como el nacimiento de la ingeniería genética es decir, veinte años después de la difusión del modelo de Watson y Crick-, cuando, en la Universidad de Stanford, del ADN viral y bacterial, sintetizado e integrado con el ADN de la bacteria escherichia coli, se produce un organismo recombinado genéticamente. A partir de allí se fundaría en 1976 Genentech, la primera empresa dedicada a la investigación genética. Dos años después, investigadores de la Universidad de Harvard desarrollaron un método químico para descifrar la construcción del ADN y por el mismo tiempo se logra una síntesis de insulina humana utilizando bacterias en condiciones de laboratorio. Hacia 1980, la Corte Suprema de los Estados Unidos dictamina que formas de vida genéticamente transformadas pueden ser patentadas, así se otorgan derechos al biólogo molecular Ananda Chakrabaty y a la General Electric por una bacteria que al alimentarse de petróleo limpia la contaminación marítima producida por derrames. A comienzos de los ochenta, plantas resistentes a virus, bacterias e insectos buscan patentarse por las firmas responsables de su producción y llegan al mercado la insulina y las hormonas de crecimiento genéticamente producidas. A mediados de esa década son clonados en la Universidad de Wisconsin los primeros animales, mientras en Dinamarca se pone en rigor la primera ley genética. En 1988, investigadores de la Universidad de Harvard obtienen las primeras patentes por animales genéticamente modificados: un ratón sensible al cáncer -oncomouse- y otro provisto con un sistema inmune humano diseñado para la investigación del SIDA. En tanto, por 1990 la empresa GenPharm desarrolla una leche de vaca transgénica que posee proteína de leche humana; por esa fecha se inicia el proyecto para el desciframiento del Genoma Humano. En el año 1992, el gobierno estadounidense informa que los alimentos genéticamente modificados no requieren de permiso especial, pues no constituirían un peligro para la salud, dos años después se comercializa el primer alimento genéticamente modificado -el tomate FlavrSavr. En 1996 es clonada en Inglaterra la oveja que origina la "tecnología Dolly", que permite producir clones desde organismos adultos y el 
suceso medial que acompaña tal noticia; finalmente, inaugura el nuevo milenio el anuncio del conocimiento del mapa del Genoma Humano. Un año después la empresa de biotecnología Advanced Cell Technology de Massachussets da a conocer la primera clonación de un embrión humano. La avalancha ya no se detiene ${ }^{3}$.

Se aprecia la velocidad con la cual la experimentación biocientífica con sus recombinaciones genéticas altera procesos que han comprendido millones de años de sucesivas transferencias de material hereditario y, del mismo modo, cómo se altera el entorno social que lo posibilitó.

Pero las consecuencias indeseadas no dejan de advertirse. A lo largo de su evolución las sociedades han requerido acoplarse a sus ambientes ecológicos y a los cuerpos sanos de sus miembros, hoy se advierte cómo ambos entornos están siendo alterados por intervenciones que se anuncian como peligros y riesgos para sociedades, comunidades, grupos y personas. Por cierto, la falta de evidencias para la mayor parte de las consecuencias nefastas que se declaran no es obstáculo para quienes indican su inevitabilidad.

Las consecuencias negativas de las biotecnologías se visualizan, en la comunicación pública, destacando equivalencias que resultan del examen de los efectos de la acción humana

\footnotetext{
3 De hecho investigadores biomédicos chinos aseguran haber clonado embriones humanos con un par de años de anterioridad. Los investigadores del Colegio Médico de Xiangya reconocen haber clonado un primer embrión en 1999, dos años antes de que la compañía estadounidense Advanced Cell Technology Inc. provocara una conmoción en el mundo científico al anunciar que había realizado ese mismo experimento. La falta de legislación y el apoyo del Gobierno chino han llevado a los investigadores de Xiangya a ir más lejos que el resto de los colegas internacionales en sus investigaciones, según una información del diario estadounidense The Wall Street Journal.
}

en el ambiente y los conflictos que los acompañan. Así, revisar el tratamiento aplicado a los problemas ecológicos ilustra las dificultades del mundo globalizado por concertar esfuerzos vinculantes para implementar programas sostenibles, que contrarresten los peligros causados por las intervenciones sociales. Se advierte que, de replicarse estos patrones, los peligros anticipados se materializarán como catástrofes, frente a las cuales, en el mejor de los casos, sólo se podrá reaccionar con reparaciones y compensaciones, pero sin ninguna capacidad para detener y orientar los espirales de problemas provocados.

Paralelamente, ante la denuncia sobre las ineficaces modalidades aplicadas para abordar los problemas ambientales, se comunican profusamente los peligros que acompañan a los avances en la decodificación del genoma humano poniéndose atención en los intereses comerciales que los guían. Los nuevos problemas encontrarían su modelo anticipatorio en la masificación de los componentes orgánicos genéticamente modificados, que colman las estanterías de los supermercados y que forman parte de nuestras culturas alimenticias, ante la ignorancia de la mayoría de sus consumidores.

En este camino, innumerables advertencias agitan temores, miedos e incertidumbres a través de alarmas públicas, locales y mundiales. Ellas denuncian los peligros que acarrean las intervenciones sobre los sistemas vivos y sus mecanismos de reproducción. En ese punto, la preocupación central se focaliza en las derivaciones de las nuevas combinaciones genéticas y sus impredecibles efectos en la ecología y la biología humana. Se acusan, en primer lugar, sus estrechas relaciones con los intereses cortoplacistas de la fama que 
motiva a muchos investigadores ${ }^{4}$, el dinero que persiguen las compañías y sus accionistas, o el poder que se produce al disponer de conocimientos clasificados. Aunque no se explicite, queda claro que los riesgos y los peligros son tan autoprovocados como las visiones optimistas de las aplicaciones de las biociencias.

Moduladas en frecuencias pesimistas o realistas, muchas de las comunicaciones acerca de las biotecnologías son intensamente amenazantes o mejor dicho: son autoamenazantes e infunden miedo. Se pronostican escenarios que congregan a la sociedad, los individuos y la biología humana ante un desenlace fatal y tales escenarios se discuten en los foros internacionales ${ }^{5}$. Las catástrofes se anticipan dramáticamente como alteraciones radicales de los ecosistemas naturales por efecto de la introducción de especies transgénicas, por potenciales efectos negativos sobre la salud de animales y seres humanos que consumen sus alimentos y ante las probables mutaciones que podrían originarse en experiencias de laboratorio ${ }^{6}$. Se destaca que ninguno de estos probables efectos

${ }_{4}$ Quienes piensan que el prestigio o la fama no tienen vigencia, deben cambiar de opinión. El presidente de la compañía ACT, que asegura haber clonado el primer embrión humano declaró que las ganas de ser los primeros en atribuirse la experiencia fue un factor clave en la decisión de publicar los resultados (EM 30/11/01) Mientras tanto, Philip Leder, padre del "oncomouse", y del cual obtuvo su patente en USA el año 1988, colocó en la puerta de su oficina el siguiente letrero "Yo hice ese ratón" (Lösh A. Genomproject und Moderne. Frankfurt/New York: Campus Verlag; 2001)

5 Tal comunidad también se reflejó en la $29^{\mathrm{a}}$ Conferencia General de la UNESCO de la que surge La Declaración Universal de la UNESCO sobre el Genoma Humano (1997)

6 Por ejemplo es inquietante que alimentos provenientes de ganado alimentado con cultivos transgénicos pueda generar en los seres humanos resistencia a los antibióticos. Recientemente, la opinión pública y el periodismo han relacionado la enfermedad de las "vacas locas" como uno de los productos de la industria del ganado. trataría de devastaciones que el tiempo corrige, sino de procesos irreversibles, en tanto la alteración de las secuencias fijadas en el patrimonio genético conllevan consecuencias que no pueden anticiparse. Podría pasar largo tiempo antes de experimentar directamente lo que nuestra especie se está haciendo a sí misma.

Otras denuncias advierten que los desastres pueden adelantarse a la explotación comercial y masiva de las innovaciones que acompañan a la biogenética. La investigación de nuevos vectores para inyectar genes con cromosomas artificiales, y que requieren ponerse a prueba en organismos vivos, bastaría para desencadenar terribles escenarios, provocando transformaciones irreversibles y daños irreparables a los componentes utilizados o afectados por tales experimentos. Estas posibilidades son perfectamente factibles por medio de las actuales tecnologías recombinantes, que permiten cruzar las fronteras genéticas yendo mucho más allá de lo que los tiempos de la evolución natural predisponen. En tal sentido, no es menor la información que indica una tasa de fracasos de la ingeniería genética que alcanza al 98\% de los casos ${ }^{7}$.

\section{Las comunicaciones amenazantes} conducen a tomar en cuenta que si bien se puede pensar en diseñar organismos perfectos, baratos y libres de enfermedades, éstos no escapan a la contingencia que acompaña la producción de nuevas expresiones de vida. Frente a lo anterior saltan señales de alarma que, siguiendo las indicaciones del filósofo Hans Jonas(4), llevan a considerar que nuestra especie, realmente, se ha convertido en un

\footnotetext{
Por ejemplo el mono rhesus bautizado como $A N D i$, que lleva un marcador de $\mathrm{ADN}$ en su genoma, es producto de una carrera que se inició con 200 óvulos de monos, de los cuales se desarrollan 40 embriones que produjeron cinco embarazos, de los cuales nacieron tres primates entre los cuales solamente $A N D i$ sobrevivió (además, el experimento fracasó pues el gen de fluorescencia verde inyectado no provocó su brillo).
} 
peligro para sí misma y, en el camino, para toda la biosfera.

\section{Latinoamérica en la globalización del peligro}

Simultáneamente a los cambios gatillados por los avances de las ciencias y tecnologías biológicas, modificaciones en el orden mundial se hacen notar en los países latinoamericanos. Específicamente, desde las últimas décadas del siglo veinte, sus centros anteriormente adscritos al sistema político y a sus praxis estatales están reconfigurándose en torno al sistema económico y a sus mercados(5). Tales cambios, que han dejado a la política y a la economía girando en torno a sus operaciones internas, aceleran la diferenciación funcional en integración planetaria, ya prevista en otras regiones y cuyo resultado es una creciente especialización de sus sistemas sociales en torno a códigos y programas que funcionan localmente en forma autónoma. Tal modalidad de estructuración global resquebraja las aspiraciones de los funcionamientos soberanos y produce, como efecto inverso, la profusión de discursos políticos y morales que claman por el restablecimiento de la unidad, puesta en entredicho por los procesos de diferenciación. En ese contexto, nuestros objetos de estudio, en tanto problemas emergentes, ingresan como un capítulo inédito dentro de las nuevas complejidades de las sociedades latinoamericanas.

Las aplicaciones biocientíficas se asocian con la globalización, tal relación se estima como su condición estructural, desde ese nuevo orden mundial se plantean sus efectos negativos para las comunidades menos protegidas. Justamente, los que están al margen de las fuentes de los problemas no sólo no participan en sus producciones sino, además, ignoran sus efectos o los desconocen. Esto quiere decir que, aunque la mayoría de nuestros países no están activos en los desarrollos de la ingeniería genética, igualmente se implican en los peligros vehiculizados por medio de sus dinámicos mercados de bienes y servicios y por la difusión, a través de los mass media, de las expectativas que los acompañan. Además, las condiciones de la interconectividad planetaria les impiden marginarse de los avances científicos y tecnológicos y mantener las posiciones de productos en los que se sustentan sus exportaciones ${ }^{8}$.

El espacio en que, hasta ahora, la comunicación biocientífica y biotecnológica es más resonante en la Región se encuentra en el área de los productos agropecuarios, es decir, en la transgenia alimentaria. El uso de semillas con resistencia a plagas, pesticidas o enfermedades y sus efectos en el organismo humano está insuficientemente establecido y no se descartan los riesgos por la alteración de las biodiversidades regionales pero, aunque se carezca de definiciones acerca de las consecuencias de estos productos, se autorizan sus explotaciones. De hecho, Argentina es un productor mundial de semillas transgénicas $\mathrm{y}$ la soja brasileña, en el mismo país, es puesta en jaque por la variedad transgénica. De este modo, las discusiones en torno a las nuevas especies que se llevan a cabo en los países centrales y que se orientan a definiciones más claras de sus riesgos, sólo transitan en Latinoamérica por los laboratorios y entre los expertos en las legislaciones que regulan el comercio internacional.

Todas estas particularidades conectan, de manera compleja, la comunicación

\footnotetext{
8 En Brasil y Chile se están realizando investigaciones que se orientan a la alteración de los genes de bacterias -Sulfolobus metallicus para la lixiviación bacteriana del cobre y la Xylella fastidiosa que afecta las plantaciones de naranjas- para actuar en forma integrada con proyectos productivos. Por otra parte, como el mayor exportador de café del mundo, empresas se unen con el estado brasileño para el mejoramiento de la producción del grano.
} 
biocientífica con las relaciones de dependencia que surgen desde la globalización. Como se señala: para bien o para mal nos vemos propulsados a un escenario que nadie comprende del todo, pero que de igual forma se hace sentir por sus efectos(6). Aceptando estas impresiones, nos distanciamos de esta declaración, agregando que parte de la confusión sólo revela que los paradigmas clásicos de las ciencias sociales son largamente superados por la novedad de los hechos que deben explicar.

Pero, ¿existen ofertas epistemológicas y teorías que estén disponibles para los observadores requeridos?

\section{Programa de observación para una realidad emergente}

Con la expansión de las producciones biogenéticas surgen preguntas pocas veces planteadas. Mientras tanto los rendimientos científicos, económicos y tecnológicos, que sitúan bajo su foco la naturaleza biológica humana, anuncian condiciones que están modificando radicalmente nuestras formas de diferenciación e inclusión social y de los mecanismos con que las sociedades se articulan. El análisis científico de estas materias tiene un evidente rezago y su tratamiento está siendo configurado por la industria cultural de la prensa, la televisión, el cine y la literatura ${ }^{9}$.

\footnotetext{
9 Como se lo describe en el filme Gattaca: experimento genético del director neozelandés Andrew Niccol (1997) o se adelantó en Un Mundo Feliz de Aldous Huxley (1932). A través de la literatura, los comics y el cine se han anticipado la posibilidad y los escenarios de la manipulación genética de la especie humana y las consecuencias de las combinaciones genéticas como en Alien 4, en La resurrección (1997) -Ripley engendra un alienígena- o en La Mosca (1986) o en la alucinante Isla del Dr. Moreau (1997). De hecho, las referencias a las manipulaciones genéticas conducen regularmente a "... algo así, como el Mundo Feliz, donde se crean los Seres Humanos para que se comporten de manera determinada...”.
}

En este sentido, quisiéramos romper con esa tendencia.

Para abordar las nuevas realidades proponemos un programa capaz de integrarse con la estructura de una sociedad policontextual y de anticipar los problemas de incomunicación entre sus constituyentes. Este observatorio se inspira en el paradigma sistémicoconstructivista, cuya fortaleza consiste en identificar a la sociedad como un sistema compuesto por comunicaciones. Esa propuesta se apoya en la teoría desarrollada por Luhmann N.(7), en los aportes de la teoría de modernización reflexiva de Beck U. (8), Robles F.(9) y en la teoría sistémica aplicada bajo la orientación de Willke H.(10) Mascareño A.(5) Estos aportes facilitan reconocer las diversas racionalidades que se colocan en juego en la comunicación genética.

Asumimos la tesis que el origen de los peligros y las expectativas atribuidas a las biotecnologías, como la comunicación de sus amenazas y controles se constituyen por mecanismos equivalentes. Se trata de operaciones comunicativas que tienen por fondo la autopoiesis de la sociedad, que están abiertas a su observación, mientras se comunican, y que, en el contexto de la diferenciación funcional no se aseguran en ningún consenso. El hecho que se debe explicar es cómo las expectativas abiertas por las biociencias se acompañan con crecientes incrementos de informaciones sobre los alcances perturbadores de sus aplicaciones y por las pugnas entre sus involucrados, sin que estos procesos alteren sus cursos. Por ejemplo, los científicos acusan a los tecnólogos de experimentar sin cautelar los efectos de sus procedimientos, estos últimos denuncian a las empresas las que, a su vez, dicen responder a las demandas por servicios de salud de personas y familias y así sucesivamente. Se trata de comprender un tipo de sistema social estructurado policéntricamente. 
La perspectiva constructivista permite absorber, comprensivamente, las innumerables facetas de nuestros objetos de atención y la multiplicidad de miradas que los configuran. Bajo su perspectiva se evita atribuir a una selección parcial -por ejemplo la científica o la económica- propiedades que la coloquen por sobre otras. Se aprecia, a través de su mirada, los efectos y consecuencias no previstas de las intervenciones biocientíficas, como los intereses contrapuestos, puestos en juego por una constelación de sistemas compuestos por la política, la economía, la ciencia, la tecnología, la justicia, la religión, la educación, la ética, los medios masivos de comunicación y la salud, entre otros. Diferenciación que los ciudadanos y consumidores experimentan con gran intensidad ante la confusión sobre los beneficios y riesgos de las biotecnologías, cuando reciben informaciones parciales que nunca pueden contrastar, si es que las pueden entender ${ }^{10}$.

El concepto de comunicación genética sitúa en perspectiva las noticias, reflexiones, expectativas y creencias que tienen por tema las problemáticas que nos interesan. Bajo sus categorías se incluyen referencias a investigaciones, aplicaciones y consecuencias de intervenciones biotecnológicas en la herencia de los sistemas vivos y a las expectativas o efectos amenazantes que se les atribuyen. Abarca desde los conocimientos que se discuten entre expertos hasta los sondeos periodísticos de la opinión pública. Desde su mirada es relevante tanto la comunicación del descubrimiento de la composición molecular de un gen, como los resultados de encuestas que señalan, por ejemplo, que estos conocimientos tienen consecuencias negativas -basándose en suposiciones sobre el eventual

${ }^{10}$ Se trata de temas que se comunican en lenguajes especializados o abiertamente confusos “...entonces no puedes formarte una opinión muy libremente... porque no entiendes...". uso por parte de los gobiernos para decretar quiénes tendrán derecho a procrear o qué bebés podrían nacer y cuáles no. Se trata de operaciones comunicativas de naturaleza social, sean éstas entrevistas a especialistas, consejos sobre nuevos remedios, discusiones religiosas o su tematización en revistas de ciencia-ficción y en el cine.

Las comunicaciones genéticas comprometen a universidades, centros de investigación, corporaciones, consorcios y empresas, instituciones públicas, agencias internacionales, organizaciones no gubernamentales, movimientos de protesta, asociaciones de consumidores y grupos de consultores. Los mass media y la comunicación de experiencias cotidianas que éstos multiplican propagan sus temas, constituyéndose en portales para selecciones que amplifican sus efectos ante la misma opinión pública, los gobiernos, comunidades y familias y de allí, nuevamente, a sus carteleras noticiosas.

Los propósitos de nuestra observación consisten en describir y explicar cómo la comunicación que trata lo genético se construye, dinámica y expansivamente, como resultado de las operaciones que concurren en la sociedad y cuyos efectos -en el lenguajeestán expuestos a la observación, actualizados bajo la forma de conocimientos. La gravitación de dichas comunicaciones consiste en que tanto las personas como los sistemas sociales actúan frente a las situaciones en arreglo a esas formas. En tanto designamos a la comunicación genética como una construcción en la sociedad, no cabe cuestionar la veracidad de sus contenidos, pues antes de todo, adquiere su realidad mediante las distinciones que la producen.

Los temas genéticos alcanzan su condición de realidad al difundirse como 
conocimientos: ¿de qué otra manera sabríamos de ellos? El Genoma Humano no es una indicación de la genética, la misma es indiferente a nuestras observaciones - ¡no así a sus manipulaciones! Todo lo referido en la comunicación genética trata de actividades sociales que puede documentarse y cuya presencia se ejemplifica con la propagación de sus temas y diversificación de su semántica. Así, por ejemplo, reconocemos, entre otras cosas, al lunes 26 de julio del año 2000 como la fecha que enuncia una de las culminaciones del Proyecto Genoma Humano -jni antes ni después!

Los fenómenos que abordamos son bioartefactos socioculturales pues, ¡ni Dolly $n i$ el maíz Bt se autoanuncian! Aunque los naturalistas insistan en que descubrir es revelar algo que preexistía, y supongan que los genes existirían antes de que fueran conocidos, no existe en la sociedad algo que no se conoce. Tanto los transgénicos como las genotecas ingresan a la sociedad desde las operaciones sociales de la ciencia experimental. Por eso, no obstante que la transgenia se aplica desde tiempos remotos para la producción de alimentos y licores, hace apenas dos o tres años esta denominación era ignorada en la opinión pública, siendo conocida solamente en los laboratorios de las empresas de biotecnologías y por los organismos encargados de regularlas. Algo equivalente sucede con la modificación de genes que, desde hace muchos años, es una consecuencia habitual de los tratamientos con radioterapia.

No obstante su relevancia, quizá por su obviedad, poco se discute acerca de lo que los conocimientos y aplicaciones biocientíficas significan socialmente, menos sobre la comprensión que conllevan sus interpretaciones o ausencia de ellas. Por ejemplo, las encuestas indican que la población chilena relaciona los alimentos transgénicos con el cáncer, pero no se conoce cómo se llegó a establecerlo. Implícitamente, científicos y políticos asumen que los temores y esperanzas provocados por las innovaciones biotecnológicas carecen de especificidad, descartando la evidencia que las sociedades encaminan sus procesos sociales sopesando, ya sea en la ignorancia como en el conocimiento, los valores colocados en juego ante sus aplicaciones. Ignoran que riesgos y expectativas son, en definitiva, construcciones socioculturales.

Lo anterior refuerza el interés por investigar las determinaciones que subyacen a las condicionalidades sistémicas. Es decir, a los códigos y programas desde donde los sistemas sociales procesan comunicaciones genéticas que pueden, o no, encontrar resonancias en otros sistemas, también autónomos y diferenciados; para los cuales su atención no dependerá de la intensidad de los problemas denunciados, sino a los criterios con arreglo a los cuales procesan sus informaciones, es decir, a las condiciones presentes en sus estructuras.

Desde este marco de observación se integran distinciones que apuntan a reconocer la creciente diferenciación social y la consecuente autonomización de los sistemas sociales capaces de autogenerar sus criterios de funcionamiento(1,7,11-13). Tal aproximación proyecta los alcances de las comunicaciones acerca de las aplicaciones de las biociencias y las saca de los discursos especializados y autorreferentes que, por su propia condición, adolecen de mecanismos apropiados para hacerse inteligibles más allá de sus fronteras. Como indican los científicos: el periodismo no logra entender ni transmitir lo que la investigación acerca del genoma humano realmente significa.

La observación de segundo orden presenta las herramientas para observar, como 
observador externo, a observadores mientras comunican el efecto de sus distinciones en sus observaciones y, resulta ser el instrumento adecuado para abordar empíricamente nuestro tema. Su conocimiento emerge mediante operaciones de descripción que indican cómo otros observan y cómo, con relación a ello, producen las indicaciones con que construyen sus mundos de realidad. Específicamente, lo distintivo del método es señalar algo con otras distinciones. Esta perspectiva metodológica permite distinguir y describir lo que los observadores, por sí mismos, no pueden distinguir ni describir, ilumina sobre sus puntos ciegos y así devuelve contingencia a sus producciones - $j$ en tanto se cambia el modo con que se observa, nada puede volver a verse igual!

\section{La comunicación genética en el contexto de la diferenciación funcional}

La comunicación genética manifiesta las vinculaciones entre los componentes de la sociedad bajo la forma de irritaciones, resonancias o informaciones. Un mismo estímulo provoca distintos efectos, así la comunicación genética se codifica, objetiva y temporalmente, como riesgo o expectativa según el sistema desde el cual se observe y de acuerdo con sus determinaciones estructurales ${ }^{11}$.

La comunicación genética se parodojiza incesantemente en la sociedad: enemigos de los alimentos transgénicos pueden apoyar la clonación terapéutica o, como se denuncia,

${ }^{11}$ Esto vale también para el tiempo, los sistemas no responden a los acontecimientos en los instantes en que éstos suceden para otros. Así muchos estudios pueden desencadenarse meses después de la ocurrencia de los sucesos que se denuncian -jatiéndanse las consecuencias de estos desfases para el caso de los fallos biotecnológicos! muchos defensores de los derechos humanos también lo son. Los ejemplos traslucen la improbabilidad de la convergencia entre múltiples observadores. Ni el ámbito legal, ni el científico, el político o cualquier otro, pueden desarrollar una observación aceptada sobre la totalidad. Cada sistema parcial trata el tema genético según sus propias determinaciones y puede ignorar operativamente lo que sucede en los otros. Un potencial de conflictos surge de estos autonomizados procesos, que interactúan con consecuencias impredecibles, frente a los cuales se reacciona por medio de comunicaciones especializadas que, por su propia condición, bloquean las posibilidades para su coordinación. Como nos señaló un científico, el conocimiento de la secuencia completa y los segmentos de ADN que codifican y no codifican para las sintesis de proteinas... es puro conocimiento. Por cierto, la situacionalidad de su declaración tiene equivalentes en los otros interlocutores sistémicos, sólo varían sus contenidos.

Dadas sus condiciones, los debates acerca de las consecuencias positivas o negativas de las aplicaciones biocientíficas surgen en los cruces de las diferentes comunicaciones que procesan los distintos sistemas sociales que operan en la sociedad y que, afectándose recursivamente de una esfera a otra, incrementan la complejidad global de la sociedad.

Se aprecia cómo la diferenciación funcional permite hacer operativas tensiones que estimulan y, simultáneamente, restringen la comunicación genética en la sociedad. En el sistema social funcionalmente diferenciado de la economía, las biotecnologías se informan como artefactos económicos. Se trata de biopatentes, bioempresas, sistemas de aseguración o capitales de riesgo. Peligros y riesgos se interpretan como externalidades 
inherentes a sus estados de desarrollo o como los costos asociados a beneficios sociales. En consecuencia, son esperables los conflictos de interpretación con los otros sistemas sociales, cuyo medio de comunicación no es el dinero.

Las operaciones orientadas por el lucro gatillan una escalada de denuncias por parte de movimientos sociales que demandan mayores controles sobre las empresas vinculadas al área genética; sin embargo, esas mismas presiones se traducen en estimular el surgimiento de mercados alternativos que desencadenan "fugas" de expertos a instituciones y países que dan más facilidades a sus trabajos. Los efectos económicos de las protestas permiten visualizar que las intervenciones parciales no paralizan procesos complejos, por el contrario, mientras se proponen controles se estudian sus evasiones y ambos procesos interactúan peligrosamente. Parece imposible substraerse al hecho que las actividades económicas no tienen muchas alternativas para rentabilizar sus inversiones, salvo las patentes. Sin duda, prohibir las patentes tiene varias caras: por un lado da una señal de límites a la investigación y coloca en duda los retornos de sus inversiones, por otro lado invisibiliza los estudios ante la mirada social. Ante ello ni la justicia, ni la política, ni la bioética tienen nada que decir ante lo que no se conoce. Como destaca Lolas(14): la dinámica propia de una línea de investigación lleva a formular preguntas cada vez más exactas y más técnicas que sólo entienden los del oficio y cuyo valor sólo pueden juzgar los pares de la disciplina. Todo queda fuera de los intereses comunicativos de la opinión pública de la sociedad.

Es interesante destacar que junto a las disputas económicas, convertidas en derechos de propiedad, empiezan a circular en los tribunales debates epistemológicos. La complejidad de la comunicación económica se incrementa ante distinciones que remueven las diferencias que distinguen entre descubrimientos e invenciones. Bajo esa forma las disputas rebotan al tema jurídico de las propiedades intelectuales y, desde allí, vuelven en la forma de rendimientos económicos como derechos exclusivos. En el camino, protestan los sistemas excluidos, como los servicios sanitarios o el político. Otros se ven afectados, como es el caso de los tiempos científicos, alterados por consideraciones comerciales que provocan la necesidad de patentar nuevos hallazgos antes que se publiquen en revistas científicas.

Pero no solamente los enfrentamientos intersistémicos incrementan la comunicación genética en la sociedad. También ocurren inesperados acoplamientos entre la investigación científica, la industria bioquímica y las políticas estatales para el desarrollo del conocimiento. El caso de la empresa Celera Genomics es emblemático. Celera, utilizando los secuenciadores desarrollados por sus empleados, en un par de años dejó atrás una década de investigaciones del Consorcio internacional PGH, subvencionado con fondos públicos de países como USA, Reino Unido, Francia, Alemania, Japón y China, logrando adelantar sustantivamente el desciframiento del código genético humano. De esta manera se comunica un paradigma de colaboración que basa su éxito en el acoplamiento de distintos intereses -por cierto, tal posibilidad solamente es viable a través de organizaciones.

En lo que respecta a la ciencia, la producción de conocimiento biocientífico encuentra sentido en sus operaciones de búsqueda. Pero su generación está condicionada -¡no determinada!- por disponibilidades económicas, nuevos instrumentos, centros universitarios de alta 
calidad y controles éticos. Hoy se aprecia cómo sus producciones, haciéndose eco de las ansiedades de la sociedad, se desacoplan de la investigación teórica al punto que, desde la misma institucionalidad científica, surgen enjuiciamientos a los estudios biogéneticos llevados a cabo en los laboratorios de las empresas. Estas disputas apuntan, nada menos que a dilucidar las fronteras entre la investigación que persigue el conocimiento de la naturaleza, y el conocimiento que posibilita la construcción de nuevas formas de vida.

Por otro lado, sin investigación no hay posibilidad alguna para desapegarse de formas de producción fundadas en los factores económicos clásicos y acoplarse a la nueva economía, fundada en la comercialización de productos cuyo valor agregado está en el conocimiento aplicado en su generación. Estas nuevas exigencias conectan al sistema educacional bajo la forma de nuevas profesiones nucleadas en torno a las biociencias, como la bioinformática o la ingeniería en tejidos que, en breve tiempo, ocuparán posiciones centrales en los proyectos universitarios.

Desde las tecnologías se comunica que los productos generados por las agrobiotecnologías constituyen la única posibilidad real para sustentar la futura población mundial y que, por lo tanto, el hambre es un problema mayor que los eventuales fallos que surgen de su desarrollo. El debate tecnológico marginado de las certezas científicas se juega socialmente en sus resonancias económicas, jurídicas y en la prensa. Su desarrollo entra en conflicto con controles sanitarios y las barreras éticas para la experimentación de nuevas sustancias en seres humanos y animales, pero no con sus entornos relevantes: los financistas o los clientes que facilitan sus operaciones. En la práctica, las producciones tecnológicas crean problemas que solamente con nuevas producciones tecnológicas podrían ser resueltas. Como se prevé, cuanto más técnica se disponga mayor dependencia se tiene con la misma - el genio liberado ya no volverá a su botella. Por otra parte, las protestas antitecnológicas no cuentan con mecanismos de discriminación, por eso su demanda de seguridad total, que vale tanto para las aplicaciones que se rechazan de plano como para las que se desean, las deslegitima. En consecuencia, la opinión pública termina por serle desfavorable. Se hace conocido, que los "errores" genéticos pueden ser responsables de miles de enfermedades hereditarias y este conocimiento impulsa a las empresas a experimentar con nuevos medicamentos. Paralelamente, se difunden estudios - $j$ aunque sea en moscas!- que informan las posibilidades de intervenir los mecanismos del envejecimiento mediante la farmacogenómica y que se equiparan a la actual "fabricación" de insulina humana.

El sistema político no está ausente en el debate que rodea las aplicaciones biogenéticas y lo recoge desde sus operaciones electorales. Pero la política carece de perspectivas globales para anticipar consecuencias indeseadas y se debate en denuncias parciales que se comunican, según sea el momento, por los opositores o por los gobernantes. En contraposición a las expectativas, no debe olvidarse que el programa democrático no anula los riesgos pues, mientras más decisores, más riesgos que deben calcularse no pueden calcularse. La participación no inhibe peligro alguno.

La política, interpretando amenazas recalificadas como demandas y apoyos, tiene dificultades para evitar una indiscriminada comunicación antigenética que, más temprano que tarde, puede afectar el desarrollo regional desencadenando inestabilidades que dificultan 
toda gobernabilidad. En tanto, la mantención de la competitividad obliga a la adopción de cambios tecnológicos, los riesgos consecuentes resultan políticamente menores que la inestabilidad social que conlleva desacoplarse de los estándares de producción exigidos. Por eso, muchos gobiernos minimizan las preocupaciones, significándolas como un lujo que no pueden permitirse países en vías de desarrollo y el estímulo a la investigación biotecnológica se constituye en una política explícita de muchos gobiernos. Hasta productores naturales consagrados buscan colocarse al día, como China Popular que comenzará pronto la explotación de arroz transgénico.

La discusión acerca de la reserva o confidencialidad de la información genética también se desplaza hacia el sistema político. El ex presidente Clinton firmó una orden prohibiendo a las reparticiones estatales contratar, promover o despedir empleados basándose en información genética. Pero esa declaración expuso públicamente la indicación sobre lo que significan los perfiles genéticos para los sistemas laborales, aseguradoras y compañías previsionales, especialmente ante la posibilidad de tener información sobre desórdenes genéticos incurables.

En el sistema de la salud las aplicaciones de las biociencias se comunican bajo la forma de nuevas medicinas que, en lugar de intervenir organismos enfermos con compuestos bioquímicos o mediante modificaciones ambientales, se dirigirán a sus estructuras y mecanismos de reproducción. Nuevas terapias y diagnósticos génicos prolongarán la vida humana e incrementarán su calidad, aunque ello también acentuará la cronicidad de tratamientos que deberán ser aceptados con resignación por pacientes que los tendrán hasta el final de sus vidas. Paralelamente, otros temas surgirán cuando se aborden consecuencias para la salud humana de las intervenciones genéticas en el mundo vegetal y animal. Puede apreciarse así el estrechamiento de los acoplamientos de la salud con las empresas, la ciencia y el desarrollo tecnológico, posibilidad que se basa en sus propias autonomías. El actual auge de las comunicaciones médicas en la sociedad guarda directa relación con estas posibilidades, y en tanto el azar que conlleva la reproducción sea regulado, éstas se proyectarán exponencialmente.

El sistema jurídico asocia los problemas emergentes de la comunicación genética a su repertorio normativo extendiendo legalidad a los riesgos, mientras se los calcule y legítimamente se decida asumirlos o se definan sus compensaciones. Sus operaciones, dispuestas para dirimir posiciones antagónicas, no pueden procesar de otra forma. La legalidad está presente en el debate sobre los derechos individuales, discutiendo sobre los sujetos de tales derechos. La discusión entre los límites de la vida entre cigotos y blastocitos, tema que se replica con la polémica acerca de la utilización de células troncales utilizando embriones, proyecta a los juristas en el debate científico, ético y religioso. Las indicaciones se multiplican y la distinción entre vida celular y vida humana transita desde los laboratorios a los tribunales. Discusiones más seculares sobre la creación de bancos de datos genéticos, que dan origen a la aceptación de "huellas genéticas", se proyectan en las doctrinas jurídicas que sostienen protecciones a la privacidad de las personas.

Las observaciones religiosas conmocionan la opinión pública discutiendo el momento de la implantación del alma en los seres humanos y el efecto de las interferencias que provocan las investigaciones y aplicaciones de las biociencias. Desde allí promueven controles jurídicos a través de modelar las opciones políticas ciudadanas en dirección de 
bloquear investigaciones científicas en "zonas sagradas". Mientras tanto, los cálculos de riesgos dejan de ser una exclusividad de las empresas aseguradoras, para acoplarse con la discusión de los temas de la democracia y la justicia.

Entre todas las comunicaciones que atañen a las aplicaciones biocientíficas la comunicación ética es la que más impresiona por sus declaraciones especiecentristas -del tipo: el genoma humano debe ser declarado patrimonio de la humanidad. Pero, no obstante su resonancia, la ética por sí misma no tiene efectos vinculantes, sólo hace suponer que algo se está haciendo, en tanto alguien debería sentirse llamado para hacerlo -si bien nada de lo que se puede hacer dejó de hacerse porque no debe hacerse. Desde el plano ético, muchas aplicaciones biotecnológicas son significadas como atentatorias para la dignidad humana y como prácticas eugenésicas que adelantan exterminios étnicos, manipulaciones políticas, económicas o familiares. Pero como se prevé, pronto los padres tendrán la opción de "mejorar" genéticamente a sus hijos, para que sean más inteligentes o más aptos. En esa dirección, desatarán una insospechada extensión de la noción de igualdad de oportunidades - ¿por qué no vivir y morir como los otros viven y mueren?

En forma específica, el programa biomédico de la ética ha dado lugar a la emergente comunicación bioética ${ }^{12}$. La comunicación bioética intenta actuar como un medio de contención que relaciona el ámbito de la investigación biológica con los otros sistemas sociales ${ }^{13}$. A través de sus operaciones

${ }^{12}$ Concepto introducido el año 1971 por el oncólogo estadounidense Van Rensselaer Potter en su libro Bioethics: Bridge to the future.

${ }^{13}$ La historia transcurrida desde la fijación de los límites a la experimentación en seres humanos hasta la limitación de las aplicaciones que surgen de la investigación genómica ilustra tal función. la bioética impregna de sentido fenómenos moleculares que carecen del mismo. Dada su propia parcialidad la bioética se coloca en posición de dar forma a la diferencia entre el poder hacer y el deber hacer en el ámbito de la investigación biomédica. En tal sentido colisiona su comunicación con la de los otros sistemas sociales y empieza a actuar por su propia representación. Este efecto es independiente de la propia autoimagen del sistema. El consenso ético, sus alcances y dictámenes específicos no podrían representar a la sociedad, aun cuando se hagan a nombre de ella y de sus intereses. Los principios de la diferenciación funcional contemporánea anulan esa posibilidad. Chocan, inclusive, con los de las propias familias que aceptan investigaciones riesgosas en tanto se exploren aplicaciones que mejoren las posibilidades de sus hijos.

Como señala Lösch(15), la autocomplejidad de la materia de la bioética queda en evidencia ante dilemas que solamente desde ella se enuncian: ¿qué tanto la humanidad es un proyecto más de la misma? (con clara referencia al proyecto Genoma Humano), ¿dónde empieza la humanidad de un ser vivo? (con referencia a los bancos de embriones), ¿qué tipo de humanidad surge de las investigaciones biocientíficas en el campo genético?, desde dónde se define la identidad humana: ¿desde una determinada relación que surge desde el dominio molecular o desde la autoidentidad del mismo en términos de un proceso de conciencia? (con referencia a que los estudios del cerebro y de la conciencia humana entran al debate bioético). En el campo jurídico la bioética ha entrado en una autoproblematización sin fronteras, por ejemplo: ¿se puede obligar a una mujer a abortar un embrión clonado, en tanto la clonación no debe ser admitida?

El autoposicionamiento del sistema de la ética como conciencia vigilante de la 
sociedad contemporánea merece un análisis especial. Aun aceptando su desligamiento de intereses religiosos, económicos, políticos, jurídicos e incluso académicos, cabe referirse a su situacionalidad en cuanto comunicación especializada en las operaciones que le dan luz, es decir, a sus propias determinaciones estructurales. Quizá una de las consecuencias funcionales de la comunicación ética es que sus irritaciones conducen a explorar alternativas, socialmente, menos controversiales para la investigación biocientífica. La bioética tiene acoplamientos estrechos con: el sistema jurídico, el político, la investigación científica, la teología, los intereses de la industria biotecnológica y los consumidores individuales de los productos médicos. Probablemente, estas consecuencias que arrastran los debates éticos multiplican sus propias oportunidades de presencia y contribuyen a explicar su actual densidad en la comunicación genética a nivel de la sociedad.

Pero no solamente los sistemas sociales maduros participan en la comunicación genética incrementando con sus conflictos de interpretaciones la complejidad de la sociedad. Sin considerar el primado de los medios de comunicación de masas en estas materias, para los sistemas de defensa la utilización de agentes biológicos como artefactos mortíferos o en manos de los bioterroristas están cambiando los modelos de conflictos bélicos y, con ello, el diseño de las organizaciones militares donde, al mismo tiempo, el secreto vuelve a tomar sus posiciones. Los artistas representan la pérdida de las armonías universales, y en el mundo del trabajo las preocupaciones sindicales se reagrupan frente a las discriminaciones para acceder a los empleos o a las carreras laborales, pues las empresas, aunque no estén en los bionegocios, podrían aplicar test genéticos para seleccionar a su personal. Los sistemas deportivos deberán redefinir los competidores autorizados, en tanto los factores que regulan las fibras y masas musculares puedan manipularse con la ingeniería genética para obtener altos rendimientos deportivos que servirían para publicitar determinadas opciones ideológicas o comerciales. Asimismo, los conflictos en torno a los derechos personales, la defensa de la vida embrionaria, el carácter público o privado de los organismos producidos por recombinaciones genéticas, se acogen en diferentes modulaciones comunicativas de ONG's y movimientos sociales que exigen legislaciones especiales, como lo hacen con respecto al comercio de productos transgénicos. Desatándose la comunicación de la desconfianza, los interpelados se deben preocupar por asegurar la inocuidad de los productos que promueven o toleran, aunque no pueden sostener el predicado "riesgo cero", porque éste ni siquiera se da en la vida hogareña; el temor y la desconfianza se constituyen en un fuerte impulso a la cautela o al desarrollo de nuevas opciones y medidas. En este sentido, la ignorancia sigue siendo un espacio de seguridad insustituible.

Las formas de operación descritas indican cómo los sistemas sociales tratan por separado, y a su modo, aquello que tiene por consecuencia efectos globales. Las hipótesis construidas sobre estas tendencias anticipan los efectos de la comunicación genética y explican cómo su emergencia en la sociedad se origina desde una red de resonancias entre sus sistemas sociales parciales.

Por cierto, las afectaciones intersistémicas tienen importantes consecuencias para la evolución social de la sociedad contemporánea. Pero, los centros tecnológicos prosiguen sus investigaciones, las empresas insisten en comercializar sus productos, los gobiernos se alinean de acuerdo con sus intereses o presiones y los consumidores seguirán exigiendo 
mayores claridades y más productos. Mientras tanto, son evidentes las dificultades para retrotraerse a formas más básicas de la integración. Por ejemplo: ¿se debe detener la investigación científica dado que no se puede prever el uso de sus aplicaciones?; ¿no es justamente la autonomización de la ciencia lo que aceleró sus producciones?; ¿cómo se la podría intervenir sin dañar sus mecanismos?; ¿cómo puede adelantarse el control ético y jurídico a la realidad científica?. En otros planos, ¿podría la economía moderna operar independiente del lucro?; ¿puede la política arriesgar su estabilidad confrontándose a las expectativas ciudadanas por mejores estándares de vida?. Las interrogantes son innumerables y sus respuestas conducen, necesariamente, a ejercitarse en la comprensión de la complejidad de la sociedad contemporánea y sus mecanismos de diferenciación funcional.

De acuerdo con las tendencias, los principios de la diferenciación funcional, mientras estabilizan las estructuras instrumentales de la sociedad aumentando su viabilidad para un nuevo estadio de complejidad, simultáneamente provocan las dificultades que obstaculizan el tratamiento de problemas globales. Por eso siguen comunicándose, de manera incontrolable, los riesgos, peligros y amenazas que se adosan a las aplicaciones biotecnológicas. Estas operaciones se incrustan con referencias a la dificultad para identificar los causantes de problemas globales advirtiéndose, en forma cada vez más notoria, que las culpabilidades también son definiciones construidas desde dominios parciales, más que sobre consensos generales. Definidos e imputados a otros, problemas aislados de sus contextos y enfrentados con medidas parciales reflejan la incapacidad para observar, integrar y comprender perspectivas distintas a la propia. Pero, como siempre existen determinaciones vinculadas a observadores y observaciones, cualesquiera que sean éstos, es inevitable que las amenazas integradas en la comunicación social no anticipen comunidades de significados.

Específicamente, las indicaciones que anuncian causas o consecuencias, plazos y coberturas, implicados o afectados, probabilidades e improbabilidades, seguridades o inseguridades, se fijan en las autorreferencias parciales puestas en juego. Esto vale para los conocimientos, creencias o ignorancias, es decir, para todo tipo de operación social. La coexistencia de distintos determinismos estructurales en los sistemas de los que se compone la sociedad explican, en parte importante, el incremento y complejización de la comunicación genética y la consecuente dificultad de su tratamiento. Dicho en sentido amplio: el despliegue de las racionalidades, puestas en juego por cada sistema autónomamente, termina ejemplificando una irracionalidad global cuya expresión en poder ha sido descrita como la peor de las tiranías: la anónima(16).

Se entiende así que problemas globales sujetos a miradas parciales, como es el caso de los peligros que conllevan las aplicaciones biocientíficas, se probabilizan por la misma evolución, en tanto éstas se guían por los procesos de diferenciación funcional. Para bien o para mal, esta evolución no se detiene. La efectiva pérdida contemporánea de la visión de totalidad desencadena un déficit estructural de racionalidad global y es uno de los puntos de partida para la comprensión de las sociedades contemporáneas.

Situándonos desde los afanes prácticos, la comprensión teórica y descripción empírica de la comunicación genética tiene consecuencias de vital importancia. La serie de decisiones con respecto a sus producciones, que son progresivamente influidas por el componente económico, científico y tecnológico de la sociedad, exigen como 
contrapartida personas, comunidades de intelectuales y culturas ciudadanas con participación activa en tales materias. De tal modo, no solamente se valora que distintos componentes sociales puedan guiar las profundas transformaciones que traen entre manos las aplicaciones biocientíficas sino que, además, cuenten con los medios para aplicar sus discernimientos. No hay mucho tiempo para ello, cuando se empieza a observar el avanzado desarrollo de los eventuales monopolios que están surgiendo de manos de bioempresas multinacionales o de instituciones financiadas con fondos públicos en países poderosos y que se concentran en la producción de conocimientos biológicos. También se observa cómo toman posiciones los monopolios cognitivos y valóricos que se movilizan desde el periodismo -en tanto que todo lo que sabe la opinión pública lo sabe a través de sus medios-y que asumen selectivamente la difusión de las reflexiones que surgen desde la ética e incluso de la comunicación religiosa.

En tal sentido, las indagaciones orientadas sistémicamente tienen un carácter estratégico, pues al contener la comunicación genética en el plano de su descripción, exponen sus distintas versiones a la observación, facilitando su reconsideración en la misma diversidad social que las origina. Desde la observación de segundo orden se puedan fijar las versiones puestas en juego, distinguir su carácter contingente mientras se estimula a explorar empíricamente el carácter de las mismas.

\section{La unidad en lo múltiple}

Como las comunicaciones que indican las expectativas, beneficios y amenazas de las intervenciones biogenéticas están sistémicamente situadas, sus contenidos específicos se modulan en forma diferenciada improbabilizando coordinaciones y acuerdos globales. Tanto los criterios de selección, que se aplican para el tratamiento de informaciones, como los tiempos requeridos en sus operaciones, potencian la incomunicabilidad global. De lo anterior surge la tesis que los sistemas sociales, por el solo hecho de operar desencadenan los déficit de racionalidad global que apreciamos en la sociedad contemporánea.

Los espacios de la irracionalidad global pueden contemplarse ante los enfrentamientos de los sistemas sociales parciales cuando aplican sus códigos especializados. En consecuencia, los problemas que surgen de la diferenciación funcional no tratan de momentáneas dificultades que con nuevas técnicas se solucionarán. De seguir estas tendencias, las posibilidades, hoy abiertas, de conducir la evolución biológica, seguirán siendo guiadas por confrontaciones azarosas de la comunicación en la sociedad.

Si se quiere intervenir esta evolución la opción disponible consiste en incrementar las resonancias intersistémicas en el ámbito de producción, difusión y aplicación de la comunicación genética, es decir: incrementar la complejidad de la sociedad. Preavances, en esta materia lo constituyen los protocolos de bioseguridad, cuyas declaraciones comprometen la participación de diferentes instancias como los ministerios de agricultura, salud, medio ambiente y comercio exterior, las entidades adscritas a éstos y los representantes de la comunidad científica, la sociedad civil, los productores agropecuarios, las organizaciones no gubernamentales, los consumidores, los ambientalistas y las empresas comerciales. En este mismo sentido, espacios deliberativos, como los propuestos desde la bioética, se posicionan favorablemente 
al exhibir sus competencias como convocantes a encuentros comunicativos. Pareciera que en esos dispositivos, y sus equivalentes, se encuentran las posibilidades disponibles para que la sociedad mundial, fuertemente diferenciada, actúe sobre los problemas globales que se autoenuncia. La observación de estos mecanismos ya se encuentra presente en actualizadas teorías de la sociedad, incluso, en algunos casos, son el fundamento de su popularidad.

De acuerdo con la revisión de Mascareño(17), neoilustrados como Habermas y Giddens proponen reencuentros de la unidad perdida y para ello ponen a disposición sus propias teorías. El primero, a través de acciones comunicativas que posibiliten tratamientos negociados (políticos) de las diferencias y, con ello, el encuentro de acuerdos racionales afianzables en el derecho; el sociólogo británico, por su parte, propugna una democracia dialógica cuyo fin es la probabilización de una sociedad fundada en la tolerancia mutua. Menos optimista que los anteriores, Beck percibe que por fuera de la sistematicidad funcional los intereses convergentes florecen desde la subpolítica. Con una orientación más sistémica, Willke promueve la constitución, bajo el alero estatal, de sistemas de deliberación que, una vez que gatillan las coordinaciones pragmáticas que los convocan, se disipan.

Estas propuestas interventoras requieren visualizar los mecanismos de construcción de las diversas comunicaciones genéticas de tal modo que los sistemas deliberantes orienten sus operaciones a un nivel superior de complejidad. Por cierto, la participación de los sistemas involucrados en un espacio comunicativo común, no elimina los determinismos estructurales que originan en sus clausuras operativas, pero permiten exponer comunicaciones que favorecen su observación y aumentan las posibilidades que distintas visiones sean tomadas en cuenta. De eso se trata el aumento de la complejidad societal. En estas materias, la centralidad del conocimiento de la comunicación genética no se agota con los discursos de sus expertos o de los voceros consagrados.

En estricto sentido, lo que se comunica sobre el ambiente, la biología o las conciencias es una construcción social. Así, todas las irritaciones son autoirritaciones en la sociedad global y todas las informaciones son autoinformaciones, hoy gobernadas por la plena contingencia. De ahí que, al describir la autoirritación que la sociedad global empieza a desarrollar frente a los temas genéticos, se entrega oportunidad para una "inteligencia frente a lo genético". Quizá, en este último sentido, se visualice, en operaciones sociales, el principio de la cautela que propuso Jonas(18).

De no tener lugar esta complejización del conocimiento comunicado relativo a la biogenética en cualquiera de sus versiones (transgénicos animales y vegetales, clonaciones reproductivas, clonaciones terapéuticas, diagnósticos génicos, farmacogenómica), se operará en esferas ignorantes de los avances que corren en paralelo. Ello, reitera la importancia de investigar los modos en que los sistemas sociales realizan su comunicación. De ahí que las estrategias orientadas a la generación de espacios de acoplamiento sean de importancia central, pues sólo por medio de ellos pueden producirse escenarios de integración de las diferencias, en donde, por ejemplo, se pondere la condena irrestricta a la investigación genética con la indicación de los inconvenientes que acompañan su paralización y viceversa. Justamente, en ese plano la modernidad alcanzará niveles de máxima racionalidad: la reflexividad de la reflexividad que surge de observar cómo se autoobserva. 


\section{Referencias}

1. Luhmann N. Soziale Systeme: Grundrisse einer allgemeinen Theorie. Frankfurt a. M: Suhrkamp; 1984.

2. Lolas F. Bioética y Antropología Médica. Santiago de Chile: Mediterráneo; 2000:11.

3. Beck U. Teoría de la modernización reflexiva. En: Berain J, comp. Las consecuencias perversas de la modernidad. Barcelona: Anthropos; 1996: 223-66.

4. Jonas H. Das Prinzip Verantwortung. Insel Verlag, Frankfurt. Barcelona: Herder SA; 1979.

5. Mascareño A. Funktionale Differenzierung und Steuerungsprobleme in Lateinamerika. Entstehung, Entwicklung und Auflösung der konzentrisch orientierten Ordnung. Bielefeld: Universität Bielefeld; 2001.

6. Giddens A. Un mundo desbocado. Los efectos de la globalización en nuestras vida. Madrid: Santillana; 2000.

7. Luhmann N. Die Gesellschaft der Gesellschaft. Suhrkamp taschenbuch wissenschaft 1360. Frankfurt am Main: Suhrkamp Taschenbuch Verlag; 1998.

8. Beck U. La teoría de la sociedad del riesgo reformulada (traducción de Fernando Robles). En: Revista Chilena de Temas Sociológicos 1998; 5(4): 11-43.

9. Robles F. Responsabilidad versus irresponsabilidad organizada. Un dilema de las sociedades de riesgo. En: Sociología y Política. Universidad Iberoamericana de México. Nueva Época 1998; (10).

10.Willke H. Systemtheorie entwickelter Gesellschaften. Dynamik und Riskanz moderner gesellscahftlicher Selbstorganisation. Weinheim/München: Juventa; 1993.

11. Rodríguez D, Arnold M. Sociedad y teoría de sistemas. Santiago de Chile: Universitaria; 1999.

12. Arnold M. Teoría de Sistemas, nuevo paradigma: Enfoque de Niklas Luhmann. Revista Paraguaya de Sociología. Centro de Estudios Sociológicos 26 (75): 51-72.

13. Arnold M, Rodríguez D. Crisis y Cambios en la Ciencia Social Contemporánea. Revista Estudios Sociales. Corporación de Promoción Universitaria (CPU) Trimestre 3 (65): 9-27.

14. Lolas F. Mas allá del cuerpo. Santiago de Chile: Andrés Bello; 1997.

15. Lösch A. Genomproject und Moderne. Frankfurt/New York: Campus Verlag; 2001. 
Comunicación Genética y Sistemas Sociales - M. Arnold

16. Arendt H. Macht und Gewalt. München; 1999.

17. Mascareño A. Diferenciación funcional en América Latina: los contornos de una sociedad concéntrica y los dilemas de su transformación. En: Persona y Sociedad 14(1); 2000: 187-207.

18. Jonas H. Técnica, medicina y ética. Barcelona: Páidos; 1997.

\section{Bibliografía}

Arnold M. Epistemologías sistémico/constructivistas y sus efectos en la investigación social. Revista de Ciencias Sociales. Sociedad Hoy. Santiago de Chile: Universidad de Concepción 1999: 93 - 100 .

Douglas M. La aceptabilidad del riesgo según las ciencias sociales. Barcelona: Páidos; 1996.

Gracia D. Fundamentos de Bioética. Madrid: Eudema; 1989.

Lee T. El proyecto Genoma Humano. Barcelona: Gedisa; 1998.

Luhmann N. Teoría de la Sociedad. Guadalajara: Universidad de Guadalajara / Universidad Iberoamericana / Instituto Tecnológico y de Estudios Superiores de Occidente; 1993.

Luhmann N. Ökologische Kommunikation: Kann die moderne Gesselschaft sich auf ökologische Gefährdungen einstellen? Opladen: Westdeutsche Verlag; 1986.

Nosal GJL. Los límites de la manipulación genética. Barcelona: Gedisa; 1999.

Potter VR. Bioethics: bridge to the future. Englewood Cliffs, N.J: Prentice-Hall; 1971.

Robles F. El desaliento inesperado de la modernidad. Santiago de Chile: Editorial RIL; 2000.

Wilson EO. Sociobiología: La nueva sintesis. Barcelona: Omega; 1980. 